\title{
Bioaugmentation enhances dark fermentative hydrogen production in cultures exposed to short-term temperature fluctuations
}

\author{
Onyinye Okonkwo ${ }^{1} \cdot$ Renaud Escudie $^{1} \cdot$ Nicolas Bernet $^{1} \cdot$ Rahul Mangayil $^{2} \cdot$ Aino-Maija Lakaniemi $^{2} \cdot$ Eric Trably $^{1}$
}

Received: 16 July 2019 / Revised: 27 September 2019 / Accepted: 19 October 2019 / Published online: 21 November 2019

(C) The Author(s) 2019

\begin{abstract}
Hydrogen-producing mixed cultures were subjected to a 48-h downward or upward temperature fluctuation from 55 to 35 or 75 ${ }^{\circ} \mathrm{C}$. Hydrogen production was monitored during the fluctuations and for three consecutive batch cultivations at $55^{\circ} \mathrm{C}$ to evaluate the impact of temperature fluctuations and bioaugmentation with synthetic mixed culture of known $\mathrm{H}_{2}$ producers either during or after the fluctuation. Without augmentation, $\mathrm{H}_{2}$ production was significantly reduced during the downward temperature fluctuation and no $\mathrm{H}_{2}$ was produced during the upward fluctuation. $\mathrm{H}_{2}$ production improved significantly during temperature fluctuation when bioaugmentation was applied to cultures exposed to downward or upward temperatures. However, when bioaugmentation was applied after the fluctuation, i.e., when the cultures were returned to $55^{\circ} \mathrm{C}$, the $\mathrm{H}_{2}$ yields obtained were between 1.6 and 5\% higher than when bioaugmentation was applied during the fluctuation. Thus, the results indicate the usefulness of bioaugmentation in process recovery, especially if bioaugmentation time is optimised.
\end{abstract}

Keywords Biohydrogen $\cdot$ Resilience $\cdot$ Synthetic mixed culture $\cdot$ Bioaugmentation time $\cdot$ Process recovery

\section{Introduction}

Biological methods for $\mathrm{H}_{2}$ production, including biophotolysis, photo fermentation, dark fermentation and biocatalysed electrolysis, have received increasing attention due to their ability to utilise renewable feedstocks such as organic wastes, plant biomass residues or sunlight for $\mathrm{H}_{2}$ generation (Hallenbeck and Benemann 2002; Dincer 2012). Among the above-stated biological $\mathrm{H}_{2}$ production methods, dark fermentation offers several advantages, such as no requirement for light, higher $\mathrm{H}_{2}$ production rates, simple bioreactor setup and wide versatility in the choice of the substrate (Chong et al. 2009; Kargi et al. 2012).

Dark fermentative $\mathrm{H}_{2}$ production can be carried out at mesophilic, thermophilic and hyperthermophilic conditions (Shin et al. 2004; Kargi et al. 2012) but is thermodynamically more favourable at higher temperatures (Zhang et al. 2014;

Onyinye Okonkwo

onyinye.okonkwo@tuni.fi

LBE, Univ Montpellier, INRA, Narbonne, France

2 Faculty of Engineering and Natural Sciences, Tampere University, Tampere, Finland
Zheng et al. 2015). In addition, thermophilic bioprocesses typically result in higher $\mathrm{H}_{2}$ production rates as well as inhibition of pathogens (Sahlström 2003) and $\mathrm{H}_{2}$ consumers such as methanogens and homoacetogens (Dessì et al. 2018b; Dessì et al. 2018a). However, decreased bacterial diversity at higher temperatures can lead to instability of the bioprocess (Westerholm et al. 2018). Thermophilic processes are typically more sensitive to temperature fluctuations and require more consistent organic loading rate than mesophilic dark fermentation processes (Angelidaki and Ahring 1994). At high loading rates, temperature of anaerobic processes can also increase due to high microbial activity (Daverio et al. 2003; Lindorfer et al. 2006). Possible upsets might also occur much faster at high temperatures due to faster microbial metabolism. However, the extent of the impact of varying bioreactor temperatures depends on the microbial communities present and the magnitude and duration of the temperature change (Okonkwo et al. 2019). A sudden, even transient temperature changes can produce varying responses in microbial populations resulting in an imbalanced metabolism and low process performance (Jiang and Morin 2007; Okonkwo et al. 2019).

In the event of unwanted temperature fluctuation, restoring the activity of the microorganisms catalysing the biological processes can be time-consuming and cost-intensive. One way to stabilise performance of a bioreactor during process 
disturbances is to augment the bioreactor with $\mathrm{H}_{2}$-producing microorganisms (Wang et al. 2008; Ren et al. 2010). Over the years, bioaugmentation has been successfully applied, for example, to reduce the start-up time of dark fermentation (Pandit et al. 2015). Bioaugmentation was shown to protect the existing microbial community from organic loading shocks and reduce the susceptibility of the $\mathrm{H}_{2}$-producing bioreactors to process disturbances (Venkata Mohan et al. 2009; Goud et al. 2014; Ács et al. 2015). In a study by Guo et al. (2010), Escherichia coli, Enterobacter aerogenes and Bacillus subtilis were separately used under mesophilic conditions to improve $\mathrm{H}_{2}$ production from organic fraction of municipal solid waste (Guo et al. 2010). In another study, Goud et al. (2014) used acidogenic bacteria to enhance the $\mathrm{H}_{2}$ production from food waste at an elevated organic load of $50 \mathrm{~g} \mathrm{~L}^{-1}$ of the waste. Bioaugmentation strategy has also been applied as a means to decrease the recovery time of anaerobic digesters stressed by organic overloading (Goud et al. 2014; Acharya et al. 2015).

Different bacterial species possess varied optimal growth requirements and capacities to cope with stress related to fluctuations in cultivation conditions such as changes in temperature or high $\mathrm{H}_{2}$ partial pressure (Pawar and van Niel 2013). Therefore, the microorganisms chosen for bioaugmentation purposes should have the desirable properties needed to perform the required function under the specific operational conditions. In our previous study, we showed that effects of temporal temperature fluctuations on dark fermentative $\mathrm{H}_{2}$ production were more severe during and after upward temperature fluctuations (from 55 to $65^{\circ} \mathrm{C}$ or $75^{\circ} \mathrm{C}$ ) than during and after downward temperature fluctuations (from 55 to $35{ }^{\circ} \mathrm{C}$ and from 55 to $45^{\circ} \mathrm{C}$ ) (Okonkwo et al. 2019). The aim of this study was to investigate the effects of augmenting thermophilic mixed cultures during and after periods of temperature shock, with a synthetic mixture of well-known $\mathrm{H}_{2}$ producers and the importance of bioaugmentation time on dark fermentative $\mathrm{H}_{2}$ production. To our knowledge, bioaugmentation with known $\mathrm{H}_{2}$-producing bacteria has not been previously studied as a means to resolve the adverse effects caused by sudden temperature fluctuations.

\section{Materials and methods}

\section{Enrichment culture and medium composition}

The inoculum used in this study was obtained from a $\mathrm{H}_{2}$-producing thermophilic $\left(55^{\circ} \mathrm{C}\right)$ continuous stirred tank reactor (CSTR), and the medium composition used is as described by Okonkwo et al. (2019). For the enrichment, anaerobically digested sludge heat treated at $90{ }^{\circ} \mathrm{C}$ for $20 \mathrm{~min}$ was used for inoculation of the CSTR by adding $10 \%$ of the sludge to a final working volume of $2 \mathrm{~L}$. The reactor was flushed with nitrogen for $5 \mathrm{~min}$ and then operated in continuous mode at hydraulic retention time of $6 \mathrm{~h}$ and at $55{ }^{\circ} \mathrm{C}$ for a period of 21 days maintaining the $\mathrm{pH}$ at 6.5 . The enriched microbial community consisted of members belonging to the genus Thermoanaerobacterium, Clostridium and Bacillus (Okonkwo et al. 2019). The medium contained the following compounds in $\mathrm{mg} \mathrm{L}{ }^{-1}: \mathrm{K}_{2} \mathrm{HPO}_{4}, 500 ; \mathrm{NH}_{4} \mathrm{Cl}, 100 ; \mathrm{MgCl}_{2} \cdot 6 \mathrm{H}_{2} \mathrm{O}, 120$; $\mathrm{H}_{8} \mathrm{FeN}_{2} \mathrm{O}_{8} \mathrm{~S}_{2} \cdot 6 \mathrm{H}_{2} \mathrm{O}, 55.3 ; \mathrm{ZnCl}_{2}, 1.0 ; \mathrm{MnCl}_{2} \cdot 4 \mathrm{H}_{2} \mathrm{O}, 2.0$; $\mathrm{CuSO}_{4}, 000.4 ;\left(\mathrm{NH}_{4}\right)_{6} \mathrm{Mo}_{7} \mathrm{O}_{24}, 1.2 ; \mathrm{C}_{\mathrm{O}} \mathrm{SO}_{4}, 1.3 ; \mathrm{H}_{3} \mathrm{BO}_{3}, 0.1$; $\mathrm{NiCl}_{2} \cdot 6 \mathrm{H}_{2} \mathrm{O}, 0.1 ; \mathrm{Na}_{2} \mathrm{O}_{3} \mathrm{Se}, 0.01 ; \mathrm{CaCl}_{2} \cdot 2 \mathrm{H}_{2} \mathrm{O}, 80$; yeast extract, 500 and $0.055 \mathrm{~mL} 37 \% \mathrm{HCl}$. The culture was fed with glucose (800 $\mathrm{mg} \mathrm{L}^{-1}$ ) and xylose $\left(1200 \mathrm{mg} \mathrm{L}^{-1}\right.$ ). Utilising both glucose and xylose is a practical way to move towards efficient bioconversion of lignocellulosic wastes to $\mathrm{H}_{2}$.

\section{Synthetic mixed culture used for bioaugmentation}

The following bacterial strains from DSMZ, Germany, were selected for bioaugmentation: Thermoanaerobacter thermohydrosulfuricus (DSM-567), Caldicellulosiruptor saccharolyticus (DSM-8903), Clostridium thermocellum (DSM-1237), Thermoanaerobacterium thermosaccharolyticum (DSM-571) and Thermotoga neapolitana (DSM-4359). All the species are strictly anaerobic thermophiles except for T. neapolitana which can tolerate low oxygen concentration (Van Ooteghem et al. 2004). Together, these bacteria form a synthetic consortium that has the following properties: thermophilic with broad range of temperatures, not auxotrophic to any amino acids and able to degrade wide range of organic substrates (Pawar and van Niel 2013). Table 1 further shows the properties of the bacteria inoculated to the synthetic mixed culture used for bioaugmentation. The bacterial strains were cultivated individually at $65{ }^{\circ} \mathrm{C}$ using the medium previously described above, and were then mixed together in a 1:1 ratio based on optical density to obtain the synthetic mixed culture. As individual cultures, the selected microorganisms are efficient $\mathrm{H}_{2}$ producers and are able to proliferate in the medium provided for this study. The synthetic culture was cultivated in batch (for 4 days) at $65{ }^{\circ} \mathrm{C}$ for three consecutive transfers to a final $\mathrm{OD}_{600}$ of 1.1 (on day 4 of the third batch cultivation cycle). The final synthetic culture was then used to study the effect of bioaugmentation during and after the temperature fluctuation periods as described in the next section. Since the bacteria in the consortium have growth temperatures ranging between 55 and $80^{\circ} \mathrm{C}, 65^{\circ} \mathrm{C}$ was considered as suitable temperature for the pre-cultivation. In addition, as our previous study showed that upward temperature fluctuations had more severe impacts on $\mathrm{H}_{2}$ production than downward temperature fluctuations (Okonkwo et al. 2019), incubation of the synthetic mixed culture at a temperature higher than $55{ }^{\circ} \mathrm{C}$ was hypothesised to provide the needed enhancement of $\mathrm{H}_{2}$ production especially in the cultures exposed to upward temperature fluctuations. 
Table 1 Properties (growth temperature, $\mathrm{pH}$ range and oxygen sensitivity) of bacteria inoculated to the synthetic mixed culture used for bioaugmentation

\begin{tabular}{lllll}
\hline Bacterial species & Temperature $\left({ }^{\circ} \mathrm{C}\right)$ & $\mathrm{pH}$ ranges & Oxygen sensitivity & References \\
\hline Thermoanaerobacter thermohydrosulfuricus & $55-75$ & $5.8-8.5$ & Obligate anaerobe & Vos et al. (2011) \\
Caldicellulosiruptor saccharolyticus & $65-75$ & $5.2-9$ & Obligate anaerobe & Vos et al. (2011) \\
Clostridium thermocellum & $60-64$ & $5.6-5.8$ & Obligate anaerobe & Vos et al. (2011) \\
Thermoanaerobacter thermosaccharolyticum & $50-80$ & $5.5-9$ & Obligate anaerobe & Vos et al. (2011) \\
Thermotoga neapolitana & $55-95$ & $5.5-9$ & Obligate anaerobe but & Jannasch et al. (1988); \\
& & & tolerates low oxygen & Van Ooteghem et al. (2004) \\
\hline
\end{tabular}

\section{Experimental procedure}

The batch experiments were carried out in gas-tight $500-\mathrm{mL}$ polypropylene centrifuge tubes $(69 \times 160 \mathrm{~mm}$, Beckman Coulter) designed for gas and liquid sampling as well as centrifugation and cultivation. The microbial inoculum used in each batch corresponded to $10 \%$ of the total working volume $(200 \mathrm{~mL})$. Each cultivation tube was flushed with nitrogen for 5 min before starting the incubation.

Prior to exposing the cultures to temporal temperature fluctuations, the mixed culture inoculum was first acclimatised to batch growth conditions by incubating at $55^{\circ} \mathrm{C}$ for $48 \mathrm{~h}$ as shown in Fig. 1. At $55^{\circ} \mathrm{C}$, the substrates were completely consumed by the end of the 48-h period. After the acclimatisation, the cultures were subjected to either downward (from 55 to $35^{\circ} \mathrm{C}$ ) or upward temperature fluctuation (from 55 to 75 ${ }^{\circ} \mathrm{C}$ ) of $48 \mathrm{~h}$ (referred to as step 1 in Fig. 1) to evaluate the impact of temperature fluctuation on $\mathrm{H}_{2}$ production. After the stress period, each culture was centrifuged for $5 \mathrm{~min}$; the spent medium was decanted and replaced with fresh medium, and the culture was then incubated again at $55{ }^{\circ} \mathrm{C}$ for $48 \mathrm{~h}$. This was carried out for altogether three consecutive batch cultivations (steps 2, 3 and 4) to estimate the $\mathrm{H}_{2}$ production recovery after the temperature fluctuations. To determine the impact of bioaugmentation, cultures exposed to similar conditions (downward or upward temperature fluctuation) were augmented with the synthetic mixed cultures described in the previous section, either during or after the temperature fluctuation period (in the beginning of step 1 or in the beginning of step 2). The reason for the different bioaugmentation times was to monitor the effect of bioaugmentation time on $\mathrm{H}_{2}$ production. As a control, batch cultivations were also carried out at $55^{\circ} \mathrm{C}$ for four consecutive cycles (steps 1 to 4 ). The cultures were either unaugmented or augmented with the synthetic mixed culture in the beginning of step 1 , to study the effect of bioaugmentation under stable incubation temperature. The synthetic mixed culture/inoculum (volume of synthetic mixed culture to volume of mixed culture inoculum) ratio that was used for enhancing $\mathrm{H}_{2}$ production during or after temperature fluctuation was 0.2. This bioaugmentation ratio was chosen, because according to Sharma and Melkania (2018), the highest cumulative $\mathrm{H}_{2}$ production and volumetric $\mathrm{H}_{2}$ production was obtained with the bacteria/sludge ratio of 0.2 and 0.25 , when they studied the effect of bioaugmentation on $\mathrm{H}_{2}$ production from organic fraction of municipal solid waste.

The $\mathrm{pH}$ during the experiments was adjusted to 6.5 , and the incubation temperatures were attained using temperaturecontrolled water baths. The experimental design described is similar to that employed by Okonkwo et al. (2019) to study the impact of temperature fluctuations on dark fermentative $\mathrm{H}_{2}$ production.

\section{Analytical techniques and calculations conducted}

Glucose, xylose, organic acid and alcohol concentrations were measured by high-performance liquid chromatography (HPLC) using a refractive index detector (Waters R410) as described previously by Monlau et al. (2013). The gas composition was analysed by a gas chromatograph (Clarus580, Perkin Elmer, Waltham, USA) equipped with a thermal conductivity detector (399152, Linde, Munich, Germany) and two columns: RtQBond to split $\mathrm{H}_{2}, \mathrm{O}_{2}, \mathrm{~N}_{2}$ and $\mathrm{CH}_{4}$ and RtMolsieve ( $5 \AA$ ) to quantify $\mathrm{CO}_{2}$. The carrier gas was argon at a pressure of 3.5 bar. The temperatures of the oven, injector and detector were 60 ${ }^{\circ} \mathrm{C}, 250^{\circ} \mathrm{C}$ and $150^{\circ} \mathrm{C}$, respectively. The gas volume and composition measurements were conducted at the respective incubation temperatures mentioned in "Experimental procedure" by retaining the cultivation bottles in the water baths during the sampling. The total volume of produced $\mathrm{H}_{2}$ was calculated at standard temperature using Eq. 1 (Logan et al. 2002).

$V_{\mathrm{H}_{2}, t}=V_{\mathrm{H}_{2}, t-1}+C_{\mathrm{H}_{2}, t}\left(V_{G, t}-V_{G, t-1}\right)+V_{H}\left(C_{\mathrm{H}_{2}, t}-C_{\mathrm{H}_{2}, t-1}\right)$

where $\mathrm{V}_{\mathrm{H}_{2}, t}$ is the cumulative $\mathrm{H}_{2}$ gas produced at time $t, V_{\mathrm{H}_{2}, t-1}$ is the cumulative $\mathrm{H}_{2}$ gas produced at $t-1, V_{G, t}$ is the total gas volume at time $t, V_{G, t-1}$ is the total gas volume at time $t-1$, $C_{\mathrm{H}_{2}, t}$ is the $\mathrm{H}_{2}$ gas fraction in the headspace at time $t, C_{\mathrm{H}_{2}, t-1}$ is the $\mathrm{H}_{2}$ gas fraction in the headspace at time $t-1$ and $V_{H}$ is the total headspace volume in the culture bottle. $\mathrm{H}_{2}$ production in moles was calculated on the basis that $1 \mathrm{~mol}$ of an ideal gas will occupy a volume of $22.4 \mathrm{~L}$ at standard temperature and pressure 
Fig. 1 Experimental set-up to study the effects of

bioaugmentation with a synthetic mixed culture on $\mathrm{H}_{2}$ production during and after temperature stress periods. All cultures were first incubated in batch at $55^{\circ} \mathrm{C}$ for $48 \mathrm{~h}$. Then, some of the cultures were subjected to a $48-\mathrm{h}$ temperature fluctuation at 35 or $75^{\circ} \mathrm{C}$ (step 1) and subsequently incubated at $55^{\circ} \mathrm{C}$ for three consecutive 48-h batch cultivation steps (steps 2, 3 and 4) (a). The experiment included also control cultures, which were incubated after the acclimatization period at $55^{\circ} \mathrm{C}$ for four consecutive batch cultivation steps with and without bioaugmentation in step 1 (b)

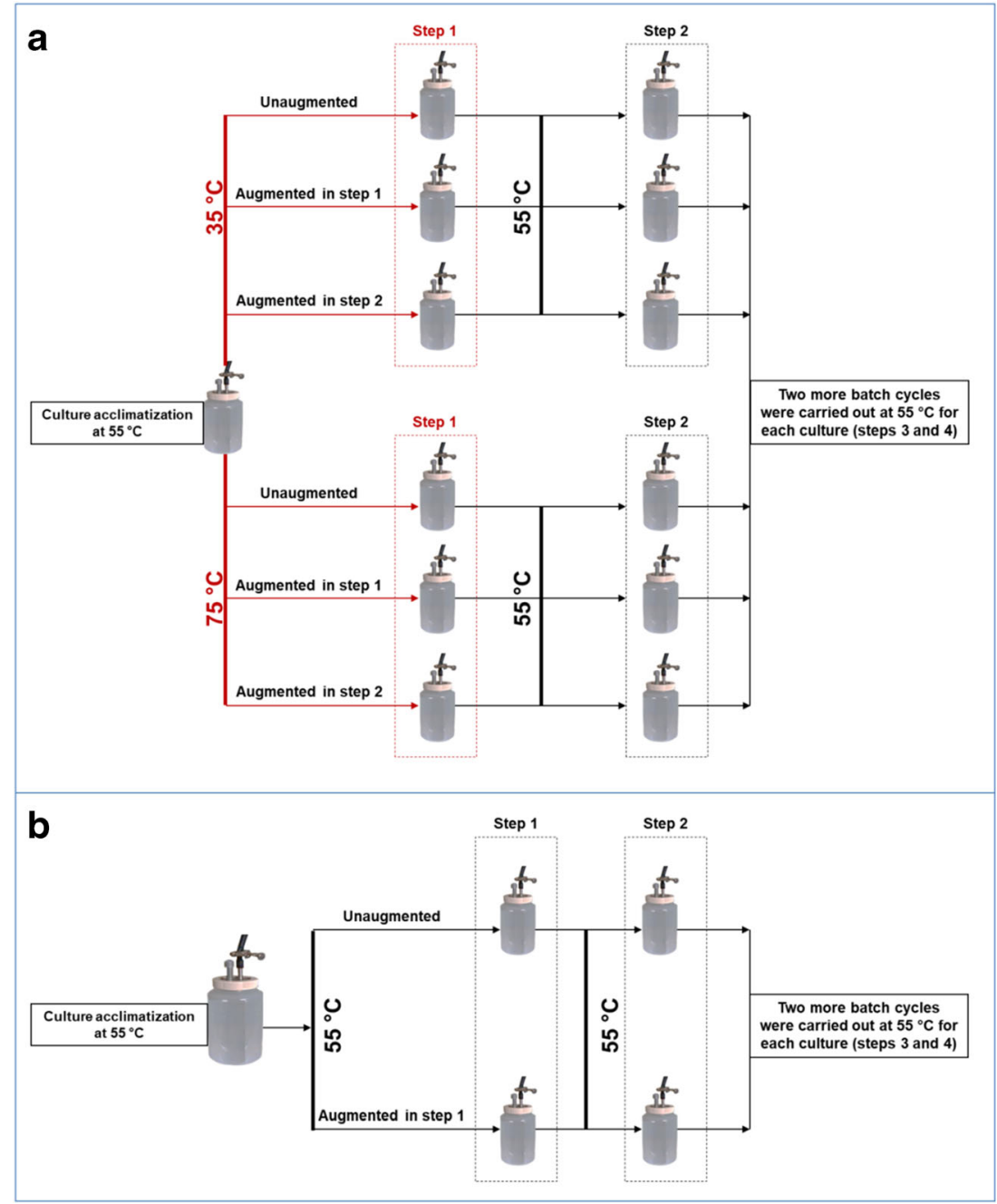

according to the ideal gas law. $\mathrm{H}_{2}$ yield was calculated by dividing the $\mathrm{mol} \mathrm{H}_{2}$ per mole of hexose equivalent using the conversion factor of 5/6 for converting xylose to its hexose equivalent. Total chemical oxygen demand (COD) of soluble compounds was calculated based on the sum of acids, ethanol and residual sugars by using the following conversion factors: $1 \mathrm{mM}$ glucose $=192 \mathrm{mg} \mathrm{COD} \mathrm{L}^{-1}, 1 \mathrm{mM}$ xylose $=160 \mathrm{mg} \mathrm{COD} \mathrm{L}^{-1}, 1 \mathrm{mM}$ acetate $=64 \mathrm{mg} \mathrm{COD} \mathrm{L}^{-1}, 1 \mathrm{mM}$ propionate $=112 \mathrm{mg}$ COD $\mathrm{L}^{-1}, 1 \mathrm{mM}$ lactate $=96 \mathrm{mg} \mathrm{COD} \mathrm{L}^{-1}, 1 \mathrm{mM}$ butyrate $=160 \mathrm{mg}$ $\mathrm{COD} \mathrm{L}^{-1}$ and $1 \mathrm{mM}^{2}$ ethanol $=96 \mathrm{mg} \mathrm{COD} \mathrm{L}^{-1}$ (Sivagurunathan and Lin 2016; Gonzales and Kim 2017). The relative $\mathrm{H}_{2}$ yield obtained during and after the temperature fluctuations was calculated using the results obtained in the unaugmented control using Eq. 2:

Relative $\mathrm{H}_{2}$ yield (\%)

$$
=\frac{\mathrm{H}_{2} \text { yield obtained during } / \text { after temperature shift }}{\text { average } \mathrm{H}_{2} \text { yield obtained from the unaugmented control }} \times 100
$$

\section{Microbial analysis for unaugmented and augmented samples during the temperature fluctuation}

Genomic DNA was extracted using the PowerSoil DNA Isolation Kit (MoBio Laboratories, Inc., Carlsbad, CA, USA) according to the manufacturer's instructions. Primers 515_532U and 909_928U (Wang and Qian 2009) including their respective linkers were used to amplify the V4_V5 region of the $16 \mathrm{~S}$ rRNA gene. The resulting products were purified and sequenced using Illumina MiSeq. Sequencing and library preparation were performed at the Genotoul Lifescience Network Genome and Transcriptome Core Facility in Toulouse, France. Sequence analysis was performed as previously described by Venkiteshwaran et al. (2016). The 16S rRNA sequences used to support the findings of this study have been deposited in the NCBI Sequence Read Archive under project file SUB6057113: MN203768-MN203978. 


\section{Results}

\section{Characterisation of bacteria in the synthetic mixed culture}

Bacteria belonging to the genera Thermoanaerobacter, Caldicellulosiruptor, Clostridium, Thermoanaerobacterium and Thermotoga were added to the synthetic mixed culture that was used for bioaugmentation in this study. After incubation of the synthetic mixed culture for three consecutive 4-day batch cultivations at $65^{\circ} \mathrm{C}$, the microbial characterisation revealed that the community included all the added bacterial genera with the exception of Clostridium (Fig. 2). Compared with all the other bacteria in the culture, Thermoanaerobacter was seen to have the highest relative abundance $(60 \%)$, followed by Thermoanaerobactium (25\%). Thermotoga and Caldicellulosiruptor had an abundance of 8 and 7\%, respectively.

\section{Comparison between augmented and unaugmented cultures at constant temperature of $55^{\circ} \mathrm{C}$}

All the substrates $\left(800 \mathrm{mg} \mathrm{L}^{-1}\right.$ glucose and $1200 \mathrm{mg} \mathrm{L}^{-1}$ xylose) added to the unaugmented control cultures incubated at constant temperature of $55{ }^{\circ} \mathrm{C}$ were consumed within the 48-h period. The $\mathrm{H}_{2}$ yield obtained from the unaugmented cultures was $1.85 \pm 0.01,1.80 \pm 0.03,1.86 \pm 0.06$ and 1.89 $\pm 0.10 \mathrm{~mol} \mathrm{H}_{2} \mathrm{~mol}^{-1}$ hexose equivalent in steps 1, 2, 3 and 4, respectively, resulting in an average $\mathrm{H}_{2}$ yield of $1.85 \pm$ $0.04 \mathrm{~mol} \mathrm{H}_{2} \mathrm{~mol}^{-1}$ hexose equivalent.

To determine the influence of bioaugmentation without any temperature stress, cultures incubated at constant temperature of $55{ }^{\circ} \mathrm{C}$ were augmented with the synthetic mixed culture in the beginning of step 1 . The $\mathrm{H}_{2}$ yield obtained in the bioaugmented control cultures was $2.19 \pm 0.08,2.07 \pm 0.06$, $2.07 \pm 0.16$ and $1.94 \pm 0.01 \mathrm{~mol} \mathrm{H}_{2} \mathrm{~mol}^{-1}$ hexose equivalent in steps 1, 2, 3 and 4, respectively. Thus, the average $\mathrm{H}_{2}$ yield was $2.07 \pm 0.09 \mathrm{~mol} \mathrm{H}_{2} \mathrm{~mol}^{-1}$ hexose equivalent. The average $\mathrm{H}_{2}$

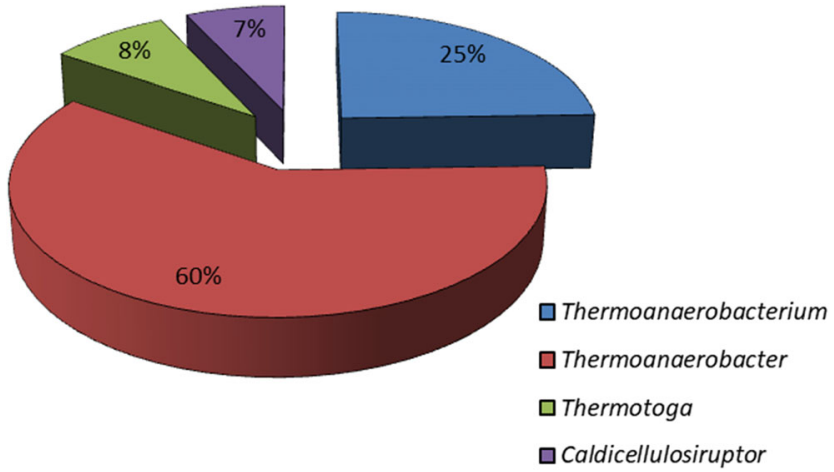

Fig. 2 Relative abundance (\%) of each genera in the synthetic mixed culture used for bioaugmentation of the native mixed culture during and after the temperature fluctuations yield obtained with bioaugmentation was significantly higher than the average yield obtained from the unaugmented control cultures. A one-way ANOVA between the unaugmented and the augmented control cultures showed that the difference in $\mathrm{H}_{2}$ yield was statistically significant $(p<0.05)$.

Bioaugmentation had also a clear impact on the distribution of the soluble metabolites. The metabolites observed in all conditions included acetate, butyrate, ethanol and traces of lactate and propionate. The unaugmented cultures had a higher percentage of butyrate in all steps (Fig. 3a), while bioaugmentation altered the metabolic profile by increasing the share of acetate production (Fig. 3b). Propionate was also detected in steps 2 and 4 in the bioaugmented cultures.

To further evaluate whether the increase in $\mathrm{H}_{2}$ production and metabolite shift was directly a result of the bioaugmentation, the microbial communities in the unaugmented and augmented cultures incubated at constant temperature of $55^{\circ} \mathrm{C}$ were evaluated using microbial samples taken in the end of incubation step 1. Based on the results obtained, the unaugmented control culture composed of Thermoanaerobacterium (73\%), Clostridium (2\%), Bacillus (10\%) and Desulfitobacterium (3\%). Other genera represented about $11 \%$ of the total relative abundance. The microorganisms found in the bioaugmented cultures included Thermoanaerobacterium (85\%), Clostridium (1\%), Bacillus (4\%) and others (10\%).

\section{Process recovery after the downward temperature shift and the impact of bioaugmentation}

A downward temperature fluctuation during dark fermentation was shown to have a negative impact on $\mathrm{H}_{2}$ production in the unaugmented cultures. The temperature shift from 55 to $35^{\circ} \mathrm{C}$ in step 1 resulted in a $\mathrm{H}_{2}$ yield of $1.35 \pm 0.13 \mathrm{~mol} \mathrm{H}_{2}$ $\mathrm{mol}^{-1}$ hexose equivalent (Fig. 4a), which is $27 \%$ lower than the average $\mathrm{H}_{2}$ yield obtained under stable conditions with the unaugmented control (Fig. 3a). After the temperature fluctuation period, the $\mathrm{H}_{2}$ yield increased gradually from step 2 to step 3 (Fig. 4a). The $\mathrm{H}_{2}$ yields obtained in steps 2, 3 and 4 (after temperature fluctuation) were $1.52 \pm 0.13,1.75 \pm 0.04$ and $1.66 \pm 0.09 \mathrm{~mol} \mathrm{H}_{2} \mathrm{~mol}^{-1}$ hexose equivalent, respectively.

Cultures to which the bioaugmentation was applied at the beginning of temperature fluctuation (step 1) gave a $\mathrm{H}_{2}$ yield of $1.84 \pm 0.04 \mathrm{~mol} \mathrm{H}_{2} \mathrm{~mol}^{-1}$ hexose equivalent during the fluctuation. The obtained $\mathrm{H}_{2}$ yield was similar to that observed with unaugmented control cultures incubated at $55^{\circ} \mathrm{C}(1.85 \pm$ $0.04 \mathrm{~mol} \mathrm{H}_{2} \mathrm{~mol}^{-1}$ hexose equivalent), which indicated that the negative impact caused by the downward temperature fluctuation could be compensated by bioaugmentation with the synthetic mixed culture. The $\mathrm{H}_{2}$ yield further increased to a maximum of $1.87 \pm 0.01 \mathrm{~mol} \mathrm{H}_{2} \mathrm{~mol}^{-1}$ hexose equivalent in step 3 when the temperature was returned to $55^{\circ} \mathrm{C}$ (Fig. 4b).

In cultures to which the bioaugmentation was applied after the temperature fluctuation (step 2), $\mathrm{H}_{2}$ yield was higher than 
Fig. 3. Hydrogen yield and the contribution of the residual sugars and soluble metabolites to the endpoint $\mathrm{COD}$ at $55{ }^{\circ} \mathrm{C}$ in $\mathbf{a}$ the unaugmented control cultures and b in the augmented control cultures. Data represents mean values and standard deviation from duplicate cultivations. The red rectangle indicates the point at which bioaugmentation was applied

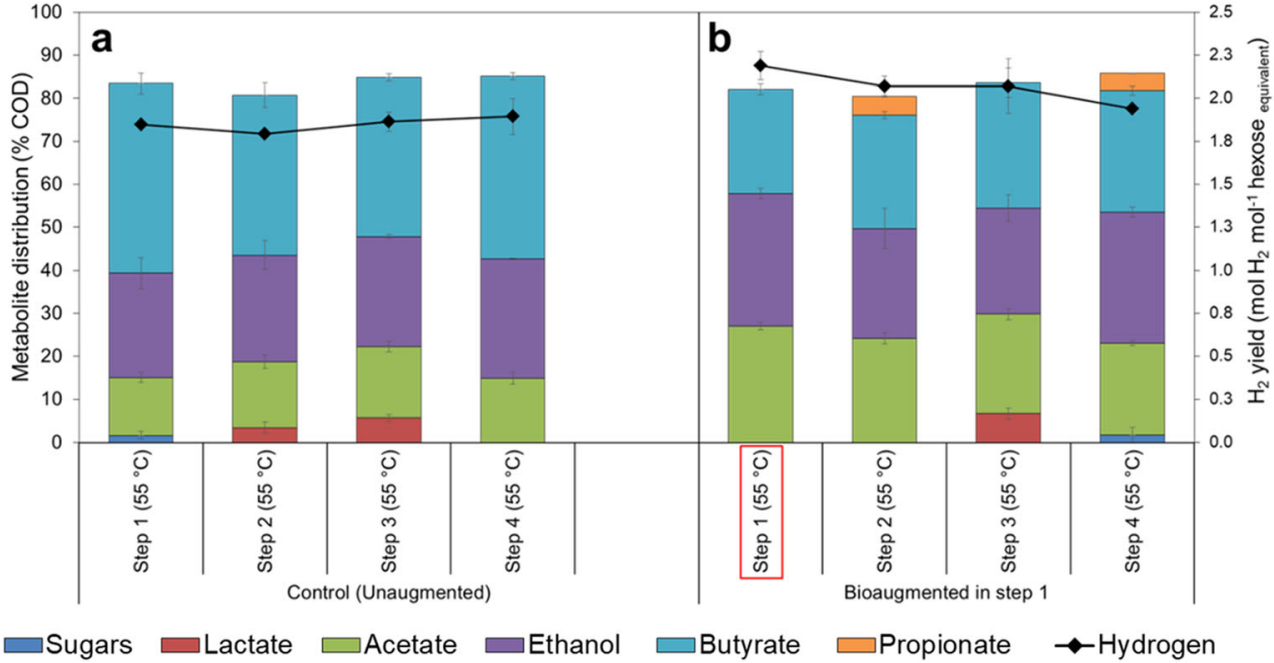

in the cultures to which the bioaugmentation was applied at the beginning of the temperature fluctuation, being $1.91 \pm$ $0.05,1.92 \pm 0.02$ and $1.92 \pm 0.01 \mathrm{~mol} \mathrm{H}_{2} \mathrm{~mol}^{-1}$ hexose equivalent in steps 2, 3 and 4, respectively (Fig. 4c).

The total soluble metabolic end-products calculated based on their COD were between 74 and $90 \%$ of the initial COD added as xylose and glucose (Fig. 4). In the unaugmented cultures, the metabolites produced during the temperature fluctuation (step 1) were acetate, butyrate, ethanol, lactate and propionate (Fig. 4a). The shift in temperature back to 55 ${ }^{\circ} \mathrm{C}$ caused a shift in the distribution of the soluble metabolic products as acetate and ethanol showed a slight increase while the concentration of lactate reduced significantly and was not at all detected in steps 3 or 4 (Fig. 4a). In cultures to which the bioaugmentation was applied during the temperature fluctuation, the share of acetate and ethanol increased significantly compared with the unaugmented cultures. Lactate slightly increased from step 1 to step 2 but was not detected in steps 3 and 4. Meanwhile, very low concentrations of propionate were also detected in steps 3 and 4 (Fig. 4b). When the bioaugmentation was applied after the temperature fluctuation, acetate and ethanol share also increased compared with the unaugmented culture. Lactate was detected in step 2 but was not detected in steps 3 and 4 (Fig. 4c), similarly to the cultures to which bioaugmentation was conducted during the fluctuation (Fig. 4b).

During the downward temperature shift, Thermoanaerobacterium spp. was less dominant in the unaugmented cultures compared with incubation at $55{ }^{\circ} \mathrm{C}$ with a share of $27 \%$, while Clostridium and Bacillus had a relative abundance of $22 \%$ and $31 \%$, respectively. Other genera accounted for $18 \%$ of the community. Bioaugmentation in the beginning of the temperature fluctuation caused an increase in the relative abundance of Thermoanaerobacterium spp. from $27 \%$ in the unaugmented culture to $72 \%$, which suggests that the Thermoanaerobacterium added was
Fig. 4 Hydrogen yield and the contribution of the residual sugars and soluble metabolites to the endpoint COD during and after the downward temperature fluctuation from 55 to $35^{\circ} \mathrm{C}$ a without bioaugmentation, $\mathbf{b}$ with bioaugmentation applied in the beginning the temperature fluctuation (step 1) and $\mathbf{c}$ with bioaugmentation applied after the temperature fluctuation in the beginning of step 2. Data represents mean values and standard deviation from duplicate cultivations. The red rectangles indicate the point at which bioaugmentation was applied

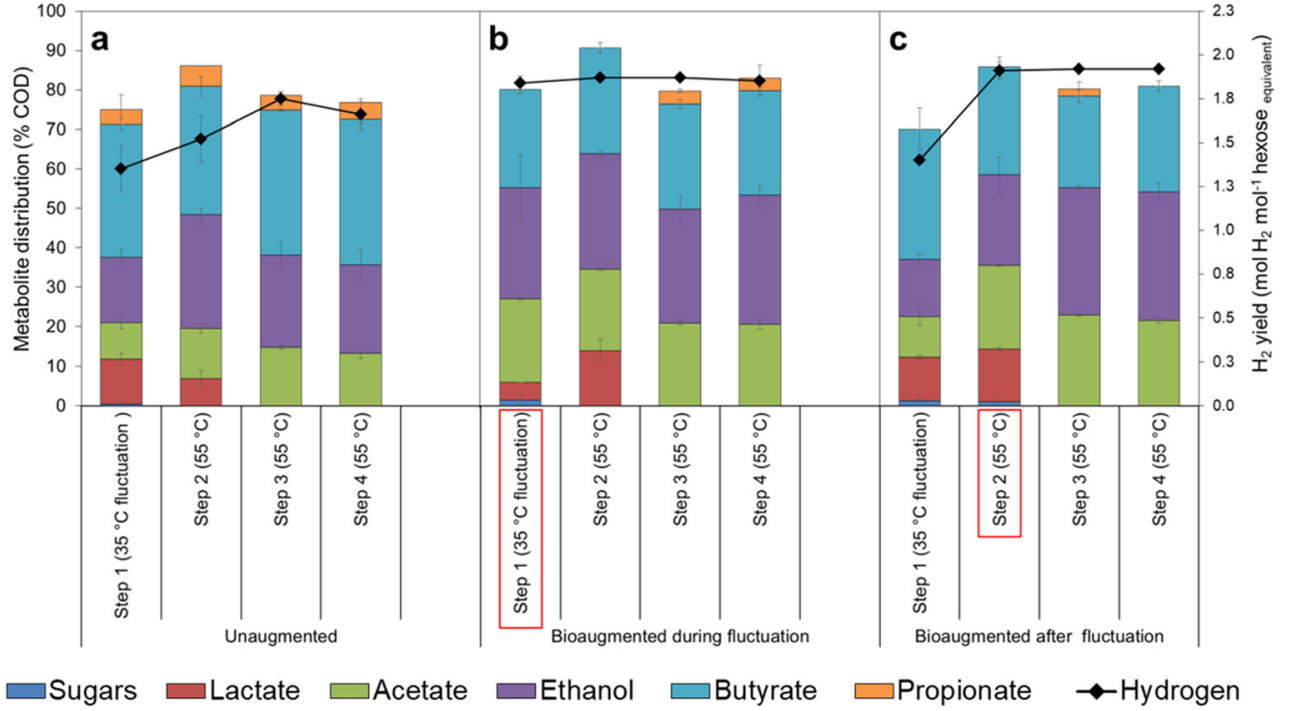


involved in $\mathrm{H}_{2}$ production during the downward temperature fluctuation despite the low temperature.

\section{Process recovery after the upward temperature shift and impact of bioaugmentation}

Upward temperature fluctuation from 55 to $75{ }^{\circ} \mathrm{C}$ was shown to have a severe impact on microbial metabolism as no $\mathrm{H}_{2}$ production was observed within the 48-h incubation period in the unaugmented culture or in the cultures to which bioaugmentation was done in the beginning of the temperature fluctuation (step 1). In the unaugmented cultures, when the temperature was taken back to $55{ }^{\circ} \mathrm{C}$ (step 2), $\mathrm{H}_{2}$ production occurred (1.27 $\pm 0.06 \mathrm{~mol} \mathrm{H}_{2} \mathrm{~mol}^{-1}$ hexose equivalent) and gradually increased to $1.43 \pm 0.08$ and $1.45 \pm 0.01 \mathrm{~mol} \mathrm{H}_{2}$ $\mathrm{mol}^{-1}$ hexose equivalent in steps 3 and 4 , respectively (Fig. $5 \mathrm{a})$. However, the highest $\mathrm{H}_{2}$ yield which was obtained in step 4 was still significantly lower (approximately $21 \%$ ) than the average $\mathrm{H}_{2}$ yield obtained under stable temperature conditions (unaugmented control at $55^{\circ} \mathrm{C}$ ).

In the cultures augmented in the beginning of the temperature fluctuation period, $\mathrm{H}_{2}$ yield was $1.45 \pm 0.05,1.74 \pm 0.13$ and $1.89 \pm 0.08 \mathrm{~mol} \mathrm{H}_{2} \mathrm{~mol}^{-1}$ hexose equivalent in steps 2,3 and 4, respectively (Fig. 5b). The $\mathrm{H}_{2}$ production was higher than in the unaugmented culture exposed to upward temperature fluctuation, and the highest $\mathrm{H}_{2}$ yield obtained (in step 4) was comparable with the $\mathrm{H}_{2}$ yield in the unaugmented control kept at $55^{\circ} \mathrm{C}$. In the cultures augmented after the temperature fluctuation period (in step 2), $\mathrm{H}_{2}$ yield was $1.53 \pm 0.06,1.76 \pm$ 0.08 and $1.93 \pm 0.04 \mathrm{~mol} \mathrm{H}_{2} \mathrm{~mol}^{-1}$ hexose equivalent in steps 2, 3 and 4, respectively (Fig. 5c).

During the upward temperature fluctuation, no VFAs and alcohols were formed in the unaugmented or in the cultures augmented in the beginning of the fluctuation, which further verified the absence of microbial activity. In the unaugmented cultures, the metabolites produced were acetate, butyrate, ethanol and lactate, when the temperature was shifted back to 55 ${ }^{\circ} \mathrm{C}$ (Fig. 5a). Butyrate had the highest share of produced soluble metabolites, followed by ethanol and acetate. Lactate, which contributed $12 \%$ in step 2 , reduced to $4 \%$ in step 4 , while the share of acetate and ethanol increased slightly. However, the contribution of butyrate remained relatively constant (Fig. 5a). In the cultures to which the bioaugmentation was applied in the beginning of the temperature fluctuation, butyrate remained the most abundant soluble metabolite (Fig. 5b). In the cultures to which the bioaugmentation was applied after the temperature fluctuation, there was also increased acetate and ethanol production observed and the share of lactate reduced gradually with each incubation step (Fig. $5 \mathrm{c})$, similar to the cultures augmented in the beginning of the fluctuation (Fig. 5b).

\section{Discussion}

In this study, it was observed that bioaugmenting native microbial communities with synthetic mixed cultures during and after upward or downward temperature fluctuation enhanced $\mathrm{H}_{2}$ production and thus limited the negative impact observed in the control cultures. Prior to the augmentation, microbial data of the synthetic mixed culture used showed differences in the microbial distribution with Thermoanaerobacter having a higher relative abundance $(60 \%)$ than the other species added, followed by Thermoanaerobacterium, Thermotoga and Caldicellulosiruptor (Fig. 2). The difference in the relative distribution observed in the synthetic mixed culture was likely a result of the different growth rates of the different bacteria at the selected growth conditions (Vanfossen et al. 2009; Yu and
Fig. $5 \mathrm{H}_{2}$ yield and the contribution of the residual sugars and soluble metabolites to the endpoint COD during and after the downward temperature fluctuation from 55 to $75^{\circ} \mathrm{C}$ a without bioaugmentation, $\mathbf{b}$ with bioaugmentation applied during temperature fluctuation (step 1) and $\mathbf{c}$ with bioaugmentation applied after temperature fluctuation in the beginning of step 2. Data represents mean values and standard deviation from duplicate cultivations. The red rectangles indicate the point at which the bioaugmentation was applied

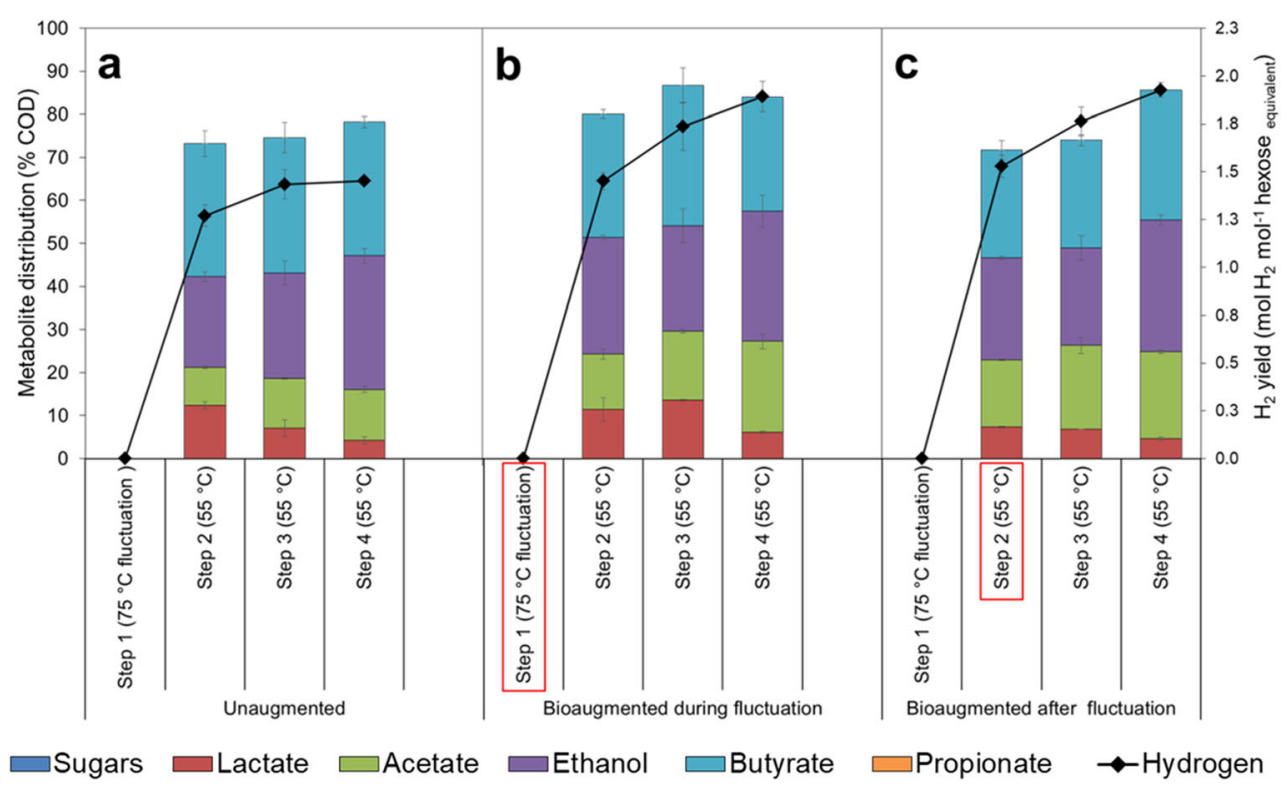


Drapcho 2011; Akinosho et al. 2014). Of all the species added to the synthetic culture, only $C$. thermocellum was not detected in the final synthetic mixed culture used for bioaugmenting. This was likely because the ability of the other bacteria to utilise xylose gave them a competitive advantage over C. thermocellum, since it does not metabolise xylose (Wilson et al. 2013) and has been shown to grow poorly on glucose (Ng and Zeikus 1982). The preferred soluble sugars of C. thermocellulum are cellulose, cellobiose or cellodextrins (Stevenson and Weimer 2005; Zhang and Lynd 2005). Therefore, $C$. thermocellulum was already lost before the bioaugmentation of the synthetic cultures (Fig. 2).

Compared with the unaugmented control culture incubated at constant temperature of $55{ }^{\circ} \mathrm{C}$, the bioaugmented control cultures demonstrated an increase in $\mathrm{H}_{2}$ production compared with the unaugmented cultures. Additionally, the relative abundance of Thermoanaerobacterium spp. increased in the augmented cultures compared with the unaugmented cultures. Relating this observation to $\mathrm{H}_{2}$ production suggests that Thermoanaerobacterium spp. had the most significant impact on the $\mathrm{H}_{2}$ production and might have influenced the increase in acetate concentration since it is capable of producing large amounts of acetate (O-Thong et al. 2008; Cao et al. 2010). The relative abundance of the other genera representing the added species was quite low (Caldicellulosiruptor had a relative abundance of $0.02 \%$, Thermoanaerobacter, $0.3 \%$ and Thermotoga, $0.04 \%)$.

For the cultures exposed to the downward temperature fluctuation, the relative $\mathrm{H}_{2}$ yield $\left(\mathrm{H}_{2}\right.$ yield compared with the unaugmented control) after the temperature fluctuation period was 5 to $10 \%$ lower than the $\mathrm{H}_{2}$ yield obtained the unaugmented control at $55{ }^{\circ} \mathrm{C}$. This implied that the downward temperature fluctuation caused a reduction in $\mathrm{H}_{2}$ yield even after three consecutive batch incubations at $55{ }^{\circ} \mathrm{C}$. Gadow et al. (2013) reported similar observations when a $\mathrm{H}_{2}$-producing stirred tank reactor operated in a continuous mode with hydraulic retention time of 10 days was exposed to 24 -h temperature fluctuation from 52 to $32^{\circ} \mathrm{C}$. They demonstrated a decrease of $27 \%$ in the $\mathrm{H}_{2}$ content during the temperature shock. Furthermore, the maximum $\mathrm{H}_{2}$ content they achieved after 10 days of recovery $\left(\right.$ at $55^{\circ} \mathrm{C}$ ) was $9 \%$ lower than the value before the temperature fluctuation. As shown in Fig. $4 c, \mathrm{H}_{2}$ production was enhanced when bioaugmentation was applied in the beginning of the temperature fluctuation (in step 1). However, based on the differences in $\mathrm{H}_{2}$ production observed with the different bioaugmentation times, the short-term temperature fluctuation also caused stress on the microorganisms used in the bioaugmentation even though the differences were not statistically significant $(p>0.05)$. Thus, in order to maximise the recovery of $\mathrm{H}_{2}$ production after downward temperature fluctuations, it seems advisable to conduct the bioaugmentation after the fluctuation period. Alternatively, repeated bioaugmentation applied as soon as an unwanted temperature fluctuation is observed and after the temperature has been restored to a desired level might also enable maximal process recovery after a temperature fluctuation period. For example, Yang et al. (2016a, b) showed improved performance of anaerobic digestion with the application of repeated bioaugmentation.

The addition of synthetic mixed cultures during or after downward temperature fluctuation showed a positive impact in the enhancement of $\mathrm{H}_{2}$ production and improved the recovery time of bacterial activity when compared with the unaugmented cultures. Comparison between the unaugmented and the augmented cultures exposed to the downward temperature fluctuation showed that Thermoanaerobacterium spp. added into the microbial consortium played a significant role in the $\mathrm{H}_{2}$ production observed during the downward temperature fluctuation. Other species present in the synthetic mixed culture used for bioaugmentation had a much lower relative abundance during the downward temperature fluctuation, as Thermoanaerobacter had a relative abundance of $0.8 \%$, Caldicellulosiruptor $0.02 \%$ and Thermotoga $0.2 \%$. Thus, they might have had little or no influence on the enhancement of $\mathrm{H}_{2}$ production, although Rafrafi et al. (2013) have reported that, despite low levels of abundance, subdominant species are able to influence the global microbial metabolic network in mixed cultures.

Cultures exposed to the upward temperature fluctuation had a completely different response to $\mathrm{H}_{2}$ production when compared with the cultures exposed to the downward temperature fluctuation. During the upward temperature fluctuation $\left(75^{\circ} \mathrm{C}\right)$, no metabolic activity was observed for the 48 -h period. However, this did not imply complete deterioration of the culture, as microbial activity was observed when the temperature was brought back to the original incubation temperature of $55{ }^{\circ} \mathrm{C}$. Nonetheless, $\mathrm{H}_{2}$ production observed was significantly lower compared with the control cultures maintained at $55^{\circ} \mathrm{C}$. It was unexpected that no $\mathrm{H}_{2}$ production was observed in the cultures augmented in the beginning of the upward temperature fluctuation as the synthetic mixed culture used for the bioaugmentation contained Caldicellulosiruptor and Thermotoga capable of producing $\mathrm{H}_{2}$ at extremely high temperatures of 70 and $80{ }^{\circ} \mathrm{C}$, respectively (Abreu et al. 2016). Additionally, based on the wide temperature and $\mathrm{pH}$ range of $T$. neapolitana, it was expected that it would have been an excellent member of the microbial community during the temperature fluctuation at $75^{\circ} \mathrm{C}$. Nonetheless, it is possible that the 48-h fluctuation period was too short for the bacteria to get adapted to the high temperature, which is why there was no sign of microbial activity observed. When comparing the cultures which were augmented at different times, higher $\mathrm{H}_{2}$ yields were obtained when the bioaugmentation was applied after the upward temperature fluctuation than when the augmentation was applied in the beginning of the temperature 
fluctuation. Although the differences in $\mathrm{H}_{2}$ yield obtained from the different bioaugmentation times were not statistically significant $(p>0.05)$, it is likely that also the bacteria used for bioaugmentation were negatively affected by the upward temperature stress. Nonetheless, bioaugmentation proved to be an effective strategy for enhancing $\mathrm{H}_{2}$ production after the temperature stress. Furthermore, the bioaugmentation is also considered important for boosting the microbial diversity especially after upward temperature fluctuations, as even shortterm upward temperature fluctuations have been demonstrated to result in loss of microbial diversity (Gadow et al. 2013; Okonkwo et al. 2019).

It was expected that Thermoanaerobacter thermohydrosulfuricus would be an active participant in the consortium during the downward or upward temperature fluctuation due to its relatively high abundance $(60 \%)$ observed in the synthetic mixed culture (Fig. 2). Furthermore, Thermoanaerobacter has been shown to grow in conditions, which are similar to the cultivation conditions used in this study (Table 1). Even though Thermoanaerobacter was the dominant genus in the synthetic mixed cultures prior to augmentation, while the results obtained from the augmented cultures showed that Thermoanaerobacterium became the most dominant species during or after bioaugmentation under all studied conditions except in unaugmented cultures undergoing downward temperature fluctuation. It is possible that the pre-existence and dominance of Thermoanaerobacterium spp. prior to augmentation ensured optimal growth/survival of the specie and better metabolic adaptation compared with the other species added in the consortium. It has been reported that Thermoanaerobacterium thermosaccharolyticum (which was among of the bacteria in the synthetic mixed culture) is able to grow at $35-37{ }^{\circ} \mathrm{C}$ if spores are first germinated at a higher temperature (Ashton 1981). Hence, the dominance of Thermoanaerobacterium spp. might have been as a result of its ability to better cope with temperature stress as opposed to the other species. As seen in Figs. 4 and 5 between unaugmented and augmented cultures, stress factors such as temperature slow adaptation time and might have prevented the activity of the other species or their proliferation. Chen et al. (2015) demonstrated that the successful application of bioaugmentation relied upon the adaptation or coexistence of the bioaugmented bacteria to indigenous microorganisms. The increase in the abundance of Thermoanaerobacterium in the augmented cultures caused a relative decrease in abundance of the other microbial genera in the consortium.

The addition of bacteria into a native consortium has been shown in previous studies to affect the metabolic distribution, and depending on the metabolic pathways utilised by the bacteria added, an additional pathway might be observed (Yang et al. 2016a). It is therefore important to choose bacteria, which are directly involved with $\mathrm{H}_{2}$ production, for bioaugmentation. Furthermore, it is likely that during the heat shock, some of the microorganisms formed spores as a mechanism to overcome the heat shock, which would explain the gradual increase in $\mathrm{H}_{2}$ yield from steps 2 to 4 after the upward temperature fluctuation. For example, Thermoanaerobacterium has been reported to form spores, which are heat resistant (Lee et al. 1993; Mtimet et al. 2016). Thus, the strengthening of a microbial consortium by bioaugmentation improves recovered activity during or after stress periods. This study demonstrated that bioaugmenting a $\mathrm{H}_{2}$-producing mixed culture with a synthetic mixed culture consisting of known $\mathrm{H}_{2}$-producing bacteria can be used as an effective approach for enhancing $\mathrm{H}_{2}$ production performance during temperature fluctuations. However, the positive effects of bioaugmentation were even higher, when it was applied after the temperature fluctuation. Thus, bioaugmentation both during and after the temperature fluctuation could also be a valid option.

Acknowledgements The authors gratefully thank Gaelle Santa-Catalina (LBE, Univ. Montpellier, INRA, Narbonne, France) for the support with the microbial community analyses.

Funding information This study was funded by the Marie SkłodowskaCurie European Joint Doctorate (EJD) in Advanced Biological Waste-ToEnergy Technologies (ABWET) under Horizon 2020 (grant no. 643071).

\section{Compliance with ethical standards}

Conflict of interest The authors declare that they have no conflict of interest.

Ethical approval This article does not contain any studies with human participants or animals performed by any of the authors.

Open Access This article is distributed under the terms of the Creative Commons Attribution 4.0 International License (http:// creativecommons.org/licenses/by/4.0/), which permits unrestricted use, distribution, and reproduction in any medium, provided you give appropriate credit to the original author(s) and the source, provide a link to the Creative Commons license, and indicate if changes were made.

\section{References}

Abreu AA, Tavares F, Alves MM, Pereira MA (2016) Boosting dark fermentation with co-cultures of extreme thermophiles for biohythane production from garden waste. Bioresour Technol 219: 132-138. https://doi.org/10.1016/j.biortech.2016.07.096

Acharya SM, Kundu K, Sreekrishnan TR (2015) Improved stability of anaerobic digestion through the use of selective acidogenic culture. J Environ Eng. https://doi.org/10.1061/(ASCE)EE.1943-7870.0000932

Ács N, Bagi Z, Rákhely G, Minárovics J, Nagy K, Kovács KL (2015) Bioaugmentation of biogas production by a hydrogen-producing bacterium. Bioresour Technol 186:286-293. https://doi.org/10. 1016/j.biortech.2015.02.098

Akinosho H, Yee K, Close D, Ragauskas A (2014) The emergence of Clostridium thermocellum as a high utility candidate for consolidated bioprocessing applications. Front Chem 2:66. https://doi.org/10. 3389/fchem.2014.00066 
Angelidaki I, Ahring BK (1994) Anaerobic thermophilic digestion of manure at different ammonia loads: Effect of temperature. Water Res. https://doi.org/10.1016/0043-1354(94)90153-8

Ashton DH (1981) Thermophilic organisms involved in food spoilage: thermophilic anaerobes not producing hydrogen sulfide. J Food Prot. https://doi.org/10.4315/0362-028x-44.2.146

Cao GL, Ren NQ, Wang AJ, Guo WQ, Xu JF, Liu BF (2010) Effect of lignocellulose-derived inhibitors on growth and hydrogen production by Thermoanaerobacterium thermosaccharolyticum W16. Int J Hydrog Energy. https://doi.org/10.1016/j.ijhydene.2009.11.127

Chen Q, Ni J, Ma T, Liu T, Zheng M (2015) Bioaugmentation treatment of municipal wastewater with heterotrophic-aerobic nitrogen removal bacteria in a pilot-scale SBR. Bioresour Technol. https://doi.org/ 10.1016/j.biortech.2015.02.022

Chong ML, Sabaratnam V, Shirai Y, Hassan MA (2009) Biohydrogen production from biomass and industrial wastes by dark fermentation. Int J Hydrogen Energy 34:3277-3287

Daverio E, Spanjers H, Bassani C, Ligthart J, Nieman H (2003) Calorimetric investigation of anaerobic digestion: Biomass adaptation and temperature effect. Biotechnol Bioeng. https://doi.org/10. 1002/bit.10595

Dessì P, Porca E, Lakaniemi AM, Collins G, Lens PNL (2018a) Temperature control as key factor for optimal biohydrogen production from thermomechanical pulping wastewater. Biochem Eng J. https://doi.org/10.1016/j.bej.2018.05.027

Dessì P, Porca E, Waters NR, Lakaniemi AM, Collins G, Lens PNL (2018b) Thermophilic versus mesophilic dark fermentation in xylose-fed fluidised bed reactors: Biohydrogen production and active microbial community. Int J Hydrog Energy 43:5473-5485. https://doi.org/10.1016/j.ijhydene.2018.01.158

Dincer I (2012) Green methods for hydrogen production. In: Int J Hydrogen Energy

Gadow SI, Jiang H, Watanabe R, Li YY (2013) Effect of temperature and temperature shock on the stability of continuous cellulosic-hydrogen fermentation. Bioresour Technol 142:304-311. https://doi.org/10. 1016/j.biortech.2013.04.102

Gonzales RR, Kim S-H (2017) Dark fermentative hydrogen production following the sequential dilute acid pretreatment and enzymatic saccharification of rice husk. Int J Hydrog Energy. https://doi.org/10. 1016/j.ijhydene.2017.08.185

Goud RK, Sarkar O, Chiranjeevi P, Venkata Mohan S (2014) Bioaugmentation of potent acidogenic isolates: a strategy for enhancing biohydrogen production at elevated organic load. Bioresour Technol. https://doi.org/10.1016/j.biortech.2014.03.049

Guo J, Wang J, Cui D, Wang L, Ma F, Chang CC, Yang J (2010) Application of bioaugmentation in the rapid start-up and stable operation of biological processes for municipal wastewater treatment at low temperatures. Bioresour Technol. https://doi.org/10.1016/j. biortech.2010.03.093

Hallenbeck PC, Benemann JR (2002) Biological hydrogen production; fundamentals and limiting processes. In: Int J Hydrogen Energy. pp $1185-1193$

Jannasch HW, Huber R, Belkin S, Stetter KO (1988) Thermotoga neapolitana sp. nov. of the extremely thermophilic, eubacterial genus Thermotoga. Arch Microbiol 150:103-104

Jiang L, Morin PJ (2007) Temperature fluctuation facilitates coexistence of competing species in experimental microbial communities. J Anim Ecol 76:660-668. https://doi.org/10.1111/j.1365-2656.2007. 01252.x

Kargi F, Eren NS, Ozmihci S (2012) Bio-hydrogen production from cheese whey powder (CWP) solution: Comparison of thermophilic and mesophilic dark fermentations. Int J Hydrog Energy. https://doi. org/10.1016/j.ijhydene.2012.02.162

Lee YE, Jain MK, Lee C, Zeikus JG (1993) Taxonomic distinction of saccharolytic thermophilic anaerobes. Int J Syst Bacteriol. https:// doi.org/10.1099/00207713-43-1-41
Lindorfer H, Braun R, Kirchmayr R (2006) Self-heating of anaerobic digesters using energy crops. Water Sci Technol. https://doi.org/10. 2166/wst.2006.246

Logan BE, Oh SE, Kim IS, Van Ginkel S (2002) Biological hydrogen production measured in batch anaerobic respirometers. Environ Sci Technol 36:2530-2535. https://doi.org/10.1021/es015783i

Monlau F, Trably E, Barakat A, Hamelin J, Steyer JP, Carrere H (2013) Two-stage alkaline-enzymatic pretreatments to enhance biohydrogen production from sunflower stalks. Environ Sci Technol. https://doi.org/10.1021/es402863v

Mtimet N, Guégan S, Durand L, Mathot AG, Venaille L, Leguérinel I, Coroller L, Couvert O (2016) Effect of pH on Thermoanaerobacterium thermosaccharolyticum DSM 571 growth, spore heat resistance and recovery. Food Microbiol. https://doi.org/ 10.1016/j.fm.2015.11.015

Ng TK, Zeikus JG (1982) Differential metabolism of cellobiose and glucose by Clostridium thermocellum and Clostridium thermohydrosulfuricum. J Bacteriol

Okonkwo O, Escudie R, Bernet N, Mangayil R, Lakaniemi A-M, Trably E (2019) Impacts of short-term temperature fluctuations on biohydrogen production and resilience of thermophilic microbial communities. Int J Hydrog Energy

O-Thong S, Prasertsan P, Karakashev D, Angelidaki I (2008) Thermophilic fermentative hydrogen production by the newly isolated Thermoanaerobacterium thermosaccharolyticum PSU-2. Int J Hydrog Energy 33:1204-1214. https://doi.org/10.1016/j.ijhydene. 2007.12.015

Pandit S, Khilari S, Roy S, Ghangrekar MM, Pradhan D, Das D (2015) Reduction of start-up time through bioaugmentation process in microbial fuel cells using an isolate from dark fermentative spent media fed anode. Water Sci Technol. https://doi.org/10.2166/wst.2015.174

Pawar SS, van Niel EWJ (2013) Thermophilic biohydrogen production: how far are we? Appl Microbiol Biotechnol 97:7999-8009. https:// doi.org/10.1007/s00253-013-5141-1

Rafrafi Y, Trably E, Hamelin J, Latrille E, Meynial-Salles I, Benomar S, Giudici-Orticoni MT, Steyer JP (2013) Sub-dominant bacteria as keystone species in microbial communities producing bio-hydrogen. Int J Hydrog Energy 38:4975-4985. https://doi.org/10.1016/j. ijhydene.2013.02.008

Ren NQ, Wang DY, Yang CP, Wang L, Xu JL, Li YF (2010) Selection and isolation of hydrogen-producing fermentative bacteria with high yield and rate and its bioaugmentation process. Int J Hydrog Energy 35:2877-2882. https://doi.org/10.1016/j.ijhydene.2009.05.040

Sahlström L (2003) A review of survival of pathogenic bacteria in organic waste used in biogas plants. Bioresour Technol 87:161-166

Sharma P, Melkania U (2018) Effect of bioaugmentation on hydrogen production from organic fraction of municipal solid waste. Int $\mathbf{J}$ Hydrog Energy. https://doi.org/10.1016/j.ijhydene.2018.03.031

Shin HS, Youn JH, Kim SH (2004) Hydrogen production from food waste in anaerobic mesophilic and thermophilic acidogenesis. Int $\mathrm{J}$ Hydrog Energy 29:1355-1363. https://doi.org/10.1016/j.jhydene. 2003.09.011

Sivagurunathan P, Lin CY (2016) Enhanced biohydrogen production from beverage wastewater: Process performance during various hydraulic retention times and their microbial insights. RSC Adv. https://doi.org/10.1039/c5ra18815f

Stevenson DM, Weimer PJ (2005) Expression of 17 genes in Clostridium thermocellum ATCC 27405 during fermentation of cellulose or cellobiose in continuous culture. Appl Environ Microbiol. https://doi. org/10.1128/AEM.71.8.4672-4678.2005

Van Ooteghem SA, Jones A, van der Lelie D, Dong B, Mahajan D (2004) $\mathrm{H}_{2}$ production and carbon utilization by Thermotoga neapolitana under anaerobic and microaerobic growth conditions. Biotechnol Lett 26:1223-1232

Vanfossen AL, Verhaart MRA, Kengen MW, Kelly RM (2009) Carbohydrate utilization patterns for the extremely thermophilic 
bacterium Caldicellulosiruptor saccharolyticus reveal broad growth substrate preferences. Appl Environ Microbiol 75:7718-7724. https://doi.org/10.1128/AEM.01959-09

Venkata Mohan S, Falkentoft C, Venkata Nancharaiah Y, Sturm BSM, Wattiau P, Wilderer PA, Wuertz S, Hausner M (2009) Bioaugmentation of microbial communities in laboratory and pilot scale sequencing batch biofilm reactors using the TOL plasmid. Bioresour Technol 100:1746-1753. https://doi.org/10.1016/j. biortech.2008.09.048

Venkiteshwaran K, Milferstedt K, Hamelin J, Zitomer DH (2016) Anaerobic digester bioaugmentation influences quasi steady state performance and microbial community. Water Res 104:128-136. https://doi.org/10.1016/j.watres.2016.08.012

Vos P, Garrity G, Jones D, Krieg NR, Ludwig W, Rainey FA, Schleifer KH, Whitman WB (2011) Bergey's manual of systematic bacteriology: Volume 3: The Firmicutes. Springer Science \& Businesse Media

Wang Y, Qian PY (2009) Conservative fragments in bacterial 16S rRNA genes and primer design for $16 \mathrm{~S}$ ribosomal DNA amplicons in metagenomic studies. PLoS One 4. https://doi.org/10.1371/journal. pone. 0007401

Wang A, Ren N, Shi Y, Lee DJ (2008) Bioaugmented hydrogen production from microcrystalline cellulose using co-culture-Clostridium acetobutylicum X9 and Ethanoigenens harbinense B49. Int J Hydrog Energy. https://doi.org/10.1016/j.ijhydene.2007.10.017

Westerholm M, Isaksson S, Karlsson Lindsjö O, Schnürer A (2018) Microbial community adaptability to altered temperature conditions determines the potential for process optimisation in biogas production. Appl Energy. https://doi.org/10.1016/j.apenergy.2018.06.045

Wilson CM, Rodriguez M, Johnson CM, Martin SL, Chu TM, Wolfinger RD, Hauser LJ, Land ML, Klingeman DM, Syed MH, Ragauskas AJ, Tschaplinski TJ, Mielenz JR, Brown SD (2013) Global transcriptome analysis of Clostridium thermocellum ATCC 27405 during growth on dilute acid pretreated Populus and switchgrass. Biotechnol Biofuels. https://doi.org/10.1186/1754-6834-6-179

Yang Z, Guo R, Shi X, He S, Wang L, Dai M, Qiu Y, Dang X (2016a) Bioaugmentation of Hydrogenispora ethanolica LX-B affects hydrogen production through altering indigenous bacterial community structure. Bioresour Technol 211:319-326. https://doi.org/10.1016/ j.biortech.2016.03.097

Yang Z, Guo R, Xu X, Wang L, Dai M (2016b) Enhanced methane production via repeated batch bioaugmentation pattern of enriched microbial consortia. Bioresour Technol. https://doi.org/10.1016/j. biortech.2016.05.062

Yu X, Drapcho CM (2011) Hydrogen production by the hyperthermophilic bacterium Thermotoga neapolitana using agricultural-based carbon and nitrogen sources. Biol Eng Transe

Zhang YHP, Lynd LR (2005) Cellulose utilization by Clostridium thermocellum: bioenergetics and hydrolysis product assimilation. Proc Natl Acad Sci U S A. https://doi.org/10.1073/pnas. 0408734102

Zhang F, Chen Y, Dai K, Zeng RJ (2014) The chemostat study of metabolic distribution in extreme-thermophilic $\left(70{ }^{\circ} \mathrm{C}\right)$ mixed culture fermentation. Appl Microbiol Biotechnol 98:10267-10273. https:// doi.org/10.1007/s00253-014-6157-x

Zheng H, Zeng RJ, Duke MC, O'Sullivan CA, Clarke WP (2015) Changes in glucose fermentation pathways by an enriched bacterial culture in response to regulated dissolved $\mathrm{H}_{2}$ concentrations. Biotechnol Bioeng. https://doi.org/10.1002/bit.25525

Publisher's note Springer Nature remains neutral with regard to jurisdictional claims in published maps and institutional affiliations. 